\title{
Pattern of congenital heart disease among children presenting to the Uganda Heart Institute, Mulago Hospital: a 7-year review
}

\author{
Judith Namuyonga ${ }^{1,2}$, Sulaiman Lubega ${ }^{1}$, Twalib Aliku' ${ }^{1}$, John Omagino ${ }^{1}$, Craig Sable ${ }^{3}$, Peter Lwabi ${ }^{1}$
}

1. Uganda Heart Institute.

2. Makerere University College of Health Sciences.

3. Children's National Medical Center, Washington DC.

\begin{abstract}
Background: Congenital heart disease (CHD) is the most common congenital anomaly in children. Over half of the deaths due to $\mathrm{CHD}$ occur in the neonatal period. Most children with unrepaired complex heart lesions do not live to celebrate their first birthday. We describe the spectrum of congenital heart disease in Uganda.

Methods: We retrospectively reviewed the data of children with CHD who presented to the Uganda Heart Institute (UHI), Mulago Hospital Complex from 2007 to 2014.

Results: A total of 4621 children were seen at the UHI during the study period. Of these, 3526 (76.3\%) had CHD; $1941(55 \%)$ were females. Isolated ventricular septal defect (VSD) was the most common CHD seen in $923(27.2 \%)$ children followed by Patent ductus arteriosus (PDA) 760 (22\%) and atrial septal defects (ASD) 332 (9.4\%).

Tetralogy of Fallot (TOF) and Truncus arteriosus were the most common cyanotic heart defects (7\% and 5\% respectively). Dysmorphic features were diagnosed in 185 children, of which 61 underwent genetic testing (Down syndrome $=24,22 \mathrm{q} 11.2$ deletion syndrome $\mathrm{n}=10$ ). Children with confirmed 22q11.2 deletion had conotruncal abnormalities.

Conclusion: Isolated VSD and Tetralogy of Fallot are the most common acyanotic and cyanotic congenital heart defects. We report an unusually high occurrence of Truncus arteriosus.

Keywords: Congenital heart disease; children; Uganda.

DOI: https://doi.org/10.4314/ahs.v20i2.26

Cite as: Namuyonga J, Lubega S, Aliku T, Omagino J, Sable C, Lwabi P. Pattern of congenital heart disease among children presenting to the Uganda Heart Institute, Mulago Hospital: a 7-year review. Afri Health Sci. 2020; 20(2): 745-752. bttps:// doi.org/10.4314/ abs.v20i2.26
\end{abstract}

\section{Introduction}

Congenital heart disease (CHD) is the most prevalent congenital abnormality and a leading cause of childhood mortality ${ }^{1}$. The estimated prevalence of CHD is 8-12/1000 live births ${ }^{2-4}$.

Without appropriate treatment, about one in three children born with significant congenital heart disease will die within the first month of life 5 . Unrepaired congenital heart disease is a major cause of heart failure among children in Africa ${ }^{6}$. We believe that this study is the largest in Africa to report on congenital heart disease amongst children. The aim of this study was to describe

\section{Corresponding author: \\ Judith Namuyonga, \\ Uganda Heart Institute, Plot Yusuf Lule Road, \\ Kampala Uganda. \\ Email: jnamuyonga@gmail.com}

the spectrum of congenital heart disease among children who presented to the Uganda Heart Institute.

\section{Methods}

We retrospectively reviewed 3526 echocardiography reports of patients with CHD that presented to the Uganda Heart Institute (UHI) between 2007 to 2014. The registry for congenital heart disease was established in 2007 by the pediatric cardiology division as part of the Ministry of Health reporting system and serves as the basis for this study. Makerere University School of Medicine Ethics and Research Committee approved the genetics component of the study.

\section{Study site}

The Institute is a 40 bed facility located within the $\mathrm{Mu}$ lago Hospital complex and has been in existence for 28 years. The UHI has a fully functional operating theatre in addition to a catheterization laboratory. It performs paediatric and adult open-heart surgeries, diagnostic 
and interventional catheterization procedures. Outpatient clinics run on a daily basis. Averagely, 60 to 80 paediatric open heart surgeries are conducted per year. A paediatric cardiology fellowship program has run since 2010.

\section{Study procedure}

Detailed transthoracic echocardiography was performed and interpreted by one of the two pediatric cardiologists (PL /SL) using standard guidelines ${ }^{7}$ with a Sonos 5500 (Philips, Best, Netherlands) and a Philips IE 33 (Philips, Best Netherlands) for the periods 2007 to 2011 and 2012 to 2014 respectively.

Difficult cases were discussed and a final diagnosis made by consensus. Digital archiving enabled cases to be reviewed and discussed with colleagues (CS) from other centers. Re-evaluation of cases at follow up improved diagnostic accuracy.

Severe congenital Heart disease, CHD was defined as complex heart abnormalities that were life-threatening. For example, heterotaxy syndromes, anomalous origin of the left coronary artery from the pulmonary artery (ALCAPA) and univentricular heart. Patient demographics including age, sex, weight and type of congenital heart defect were entered into an Excel spreadsheet and analyzed using SPSS version 16. Pulse oximetry readings were available for only a small subset of children and not included in the analysis.

\section{Syndromic children}

If the child had an obvious syndromic condition based on clinical examination, they were sent for genetics assessment. Genetics testing was done by a highly experienced genetics specialist from Washington DC, United States together with the Ugandan team and the paediatric cardiologist (CS) during some missions. Genetics diagnosis was based on clinical presentation of the common genetics syndromes with associated complications. These were matched with the echocardiogram diagnosis. We secured Institutional Ethical approval from the Makerere School of Medicine as well as from the $\mathrm{Na}$ tional Institute of Health (NIH) laboratory in Washington DC, United States to run detailed microarray and DNA sequencing for the genetics study but blood sam- ples were not taken off or sent for analysis. The team relied on clinical diagnosis by a highly skilled genetics specialist. Syndromes such as Down's syndrome, 22q11 deletion syndrome, Holt Oram and Williams syndrome were diagnosed. Children with Holt Oram syndrome had upper limb abnormalities in addition to the CHD. A genetics syndrome was diagnosed based on clinical evaluation, the results were given to the family, and was counseled by our team, a geneticist and genetic counselor.

\section{Congenital Rubella Syndrome}

Congenital Rubella syndrome, CRS was diagnosed based on clinical features of cataracts, microphthalmia, microcephaly and hearing impairment. Retrospective data was obtained from the World Health Organization -Congenital Rubella (WHO- CRS) Surveillance that was conducted at the UHI in 2014. CRS was confirmed by blood samples obtained from the child and mother. Serum was tested at Uganda Virus Research Institute (UVRI) for evidence of active rubella virus infection through identification of rubella-specific IgM antibodies. UVRI is a government parastatal certified by the American College of Pathologist to conducts research, surveillance and diagnostics linked to viral etiology and provides expert advice ${ }^{8}$.

\section{Results}

Overall, 4621 charts were reviewed during the study period. A diagnosis of congenital heart disease was made in 3526 (76.3\%) children. The majority 1941(55\%) were females. Most patients presented during infancy (range 1 day -18 years).

VSD was the most prevalent defect (921) of which 702 children $(76 \%)$ had perimembranous VSD, and 79 $(8.5 \%)$ had muscular VSD. PDA was the second most commonly occurring defect seen in 760 cases $(22 \%)$. ASD was present in 332 children $(9.4 \%)$ with the Ostium secundum type occurring in 293 (88\%) followed by the sinus venosus defect, $23(6.9 \%)$.

Tetralogy for Fallot and persistent Truncus arteriosus were the most common cyanotic heart diseases. Some defects occurred in small percentages and have been reported. Children with syndromes in the study were examined for specific genetic abnormalities. 
Table 1: Acyanotic heart diseases

\section{Number Overall Percentage in Mean age Female $n$ \\ CHD (\%) $\mathrm{N}=3526 \quad$ (months)/years $\quad(\%)$}

\begin{tabular}{lcccc}
\hline Isolated VSD & 921 & 26 & $25(2)$ & $484(52)$ \\
PDA & 760 & 22 & $19(1.6)$ & $478(62)$
\end{tabular}

\begin{tabular}{|c|c|c|c|c|}
\hline ASD & 332 & 9.4 & $51(4)$ & $188(56)$ \\
\hline ECD & 265 & 8 & $17(1)$ & $164(62)$ \\
\hline $\begin{array}{l}\text { Pulmonary } \\
\text { valve stenosis }\end{array}$ & 226 & 6 & $38(3)$ & $99(44)$ \\
\hline $\begin{array}{l}\text { Mitral valve } \\
\text { prolapse }\end{array}$ & 63 & 2 & $90(7.5)$ & $44(69)$ \\
\hline $\begin{array}{l}\text { Aortic valve } \\
\text { stenosis }\end{array}$ & 35 & 0.9 & $100(8)$ & $14(40)$ \\
\hline PAPVC & 17 & 0.5 & $46(4)$ & $5(29)$ \\
\hline COA & 14 & 0.4 & $80(6.5)$ & $7(50)$ \\
\hline
\end{tabular}

Among the cyanotic defects, Tetralogy of Fallot (TOF) was the most common, 247 cases $(7 \%)$ were seen with a male preponderance.

Table 2: Cyanotic heart diseases

\begin{tabular}{lllll}
\hline Lesion & Numbers & $\begin{array}{l}\text { Mean age } \\
\text { Years } \\
\text { (months) }\end{array}$ & $\begin{array}{l}\text { Female } \\
\text { Number (\%) }\end{array}$ & $\begin{array}{l}\text { Overall } \\
\text { percentage in } \\
\text { CHD } \\
\text { (N=3526) }\end{array}$ \\
\hline Tetralogy of Fallot & 247 & $4(50)$ & $110(44)$ & $\mathbf{7}$ \\
Truncus arteriosus & 165 & $0.4(5)$ & $92(56)$ & $\mathbf{5}$ \\
DORV & 104 & $1.4(16.5)$ & $56(53)$ & $\mathbf{3}$ \\
Pulmonary atresia & 71 & $2.6(32)$ & $38(53)$ & $\mathbf{2}$ \\
Tricuspid atresia & 62 & $1.6(20)$ & $31(50)$ & $\mathbf{1 . 8}$ \\
\hline D TGA & 53 & $0.7(9.5)$ & $21(40)$ & $\mathbf{1 . 5}$ \\
A PVR & 8 & $0.5(7)$ & $4(50)$ & $\mathbf{0 . 2}$ \\
\hline
\end{tabular}

D TGA-Transposition of the Great Arteries, APVR- anomalous pulmonary venous return, DORV-Double outlet right ventricle 
In addition, sub types of DORV

DORV was diagnosed in 104 children. DORV with sub pulmonic VSD, also called the Taussig Bing anomaly, occurred in 43 children (41\%). DORV with sub aortic
VSD (VSD physiology), 38 (37\%), DORV/ pulmonary stenosis (Fallot type) 15 (14\%), and DORV with doubly committed VSD found in $3(3 \%)$. Two $(2 \%)$ children had DORV with corrected TGA.

Table 3: Complex heart defects

Most children with complex heart defects were female.

\begin{tabular}{lll}
\hline Defect & Total number & $\begin{array}{l}\text { Female } \\
\text { Number (\%) }\end{array}$ \\
\hline $\begin{array}{l}\text { Dextrocardia with left } \\
\text { isomerism }\end{array}$ & 14 & $10(71.4)$ \\
Hypoplastic left heart & 10 & $7(70)$ \\
syndrome (HLHS) & & \\
Ebstein's anomaly & 7 & $4(57)$ \\
ALCAPA & 3 & $1(33)$ \\
Univentricular heart & 12 & $6(50)$ \\
\hline
\end{tabular}

ALCAPA-Anomalous origin of the left coronary artery from the pulmonary artery

\section{Less common CHDs}

Some congenital defects were rare, namely: Aortopulmonary window, which was present in $6(0.2 \%)$ of all CHD. Common atrium $13(0.3 \%)$ with a female preponderance 10 (76\%). Partial Anomalous Pulmonary venous connections (PAPVC) were present in 17 $(0.5 \%)$. It commonly occurred with the sinus venous ASD. Median odiagnosis was 3 years (range 1 month12 years). Bicuspid aortic valve occurred in $7(0.2 \%)$ of all congenital heart disease.

Total anomalous pulmonary venous connections (table 2) were reported in only 8 children (3\%); 2 had the in- fracardiac type, 4 cardiac type and 2 the supra cardiac type.

\section{Patients with dysmorphic features}

One hundred eighty-five children had dysmorphic features. The majority 143 (76\%), had a phenotypic diagnosis of Trisomy 21 (Down syndrome) with endocardial cushion defects as the most likely diagnosis. Sixty-one of the 186 children underwent genetic testing. Congenital Rubella Syndrome was present in 15 (8) \% of cases from data extracted from the WHO-UHI-CRS Surveillance in 2014. Eighty-eight percent had CHD, 68\% had ocular defects (cataracts) and 20\% had hearing problems. PDA was the most common CHD (77\%). 
Table 4: Genetic abnormalities

\begin{tabular}{|l|l|}
\hline Genetic disorder & N=61 \\
\hline Trisomy 21 & 24 \\
\hline 22q11.2 deletion syndrome & 10 \\
\hline Noonan syndrome & 5 \\
\hline Turner syndrome & \\
\hline Kabuki & 3 \\
\hline Holt Oram & 2 \\
\hline CHARGE & 1 \\
\hline Unrecognized dysmorphism & 1 \\
\hline
\end{tabular}

Of the children with 22q11.2 deletion syndrome, 7 had Tetralogy of Fallot, 2 Truncus Arteriosus and 1 had DTGA. Noonan's syndrome was confirmed in 5 children; 4 had pulmonary stenosis.

\section{Congenital heart defects and age at diagnosis}

Most complex heart diseases such as univentricular heart defects, D-TGA, pulmonary atresia, tricuspid atresia, total anomalous pulmonary venous connections and Ebstein's anomaly were rarely diagnosed after the first year of life. Notably, no children with right isomerism/ heterotaxy were seen during the study period.

Table 5: Congenital heart abnormalities and age at diagnosis

\begin{tabular}{|l|l|l|l|}
\hline Abnormality & Infancy & $(>\mathbf{1}<\mathbf{5}$ years $)$ & $>\mathbf{5}<\mathbf{1 8 Y e a r s}$ \\
\hline VSD & 615 & 190 & 116 \\
\hline PDA & 556 & 138 & 66 \\
\hline ASD & 134 & 114 & 84 \\
\hline Pulmonary Stenosis & 130 & 69 & 54 \\
\hline ECD & 165 & 45 & 55 \\
\hline COA & 6 & 2 & 6 \\
\hline TOF & 83 & 98 & 66 \\
\hline Truncus Arteriosus & $144^{*}$ & 20 & 1 \\
\hline DORV & 72 & 18 & 8 \\
\hline
\end{tabular}

*Diagnosed before 6 months of age 
VSD, ASD, PDA, TOF, pulmonary stenosis and coarctation of the aorta continued to present in children older than 5 years. Defects not commonly diagnosed after 6 months included; Truncus arteriosus, DORV, Tricuspid atresia, TGA, anomalous pulmonary venous return and Hypoplastic left heart syndrome.

\section{Discussion}

This was a retrospective study with a large number of patients making it representative of the entire country. Ventricular septal defects (VSD) were the most common congenital heart defects $(26 \%)$ with the membranous type in high frequency. Our findings are similar to studies reported elsewhere ${ }^{4,9-11}$. Ekure and colleagues reported VSDs in $25 \%$ of Nigerian children ${ }^{12}$ however, a higher prevalence stated in some studies notably Cameroon, included adults attesting to the fact that VSD patients survive into adulthood ${ }^{6,13}$. VSD is one of those defects that were diagnosed till 18 years.

Patent Ductus Arteriosus was the second most common defect. This may be due to increased number of premature deliveries, genetic syndromes, maternal rubella infection and peripartum hypoxia ${ }^{12,13}$. PDA is highly prevalent in extreme preterm babies with birth weight less than $1 \mathrm{~kg}^{14}$ Premature deliveries in Uganda directly eminent from multiple factors including; low and late antenatal attendance for the recommended visits hence mothers tend to miss drugs like Fansidar that are prophylactic for malaria. Premature deliveries have been linked to placental malaria in some studies, poor maternal preconception nutriton and adolescent pregnancies as well as child spacing less 24 months ${ }^{15,16}$. Anemia and gestational hypertension are the highest risk factors for preterm deliveries ${ }^{15}$.

PDA is one of the cardiac manifestations of Congenital Rubella syndrome reported in infants whose mothers suffered Rubella infection during pregnancy ${ }^{17}$. Other abnormalities include; VSD, peripheral pulmonary branch stenosis, ocular complications and central nervous system problems ${ }^{18}$. A recently concluded World Health Organization Congenital Rubella Surveillance in Uganda showed a high percentage $(77 \%)$ of PDAs in those infants with serologically confirmed Congenital Rubella Syndrome ${ }^{19}$.

At present, Uganda lacks a National rubella vaccination program, developed countries vaccinate children with the MMR (Mumps Measles Rubella vaccine which drastically dropped CRS incidence ${ }^{20}$.

Atrial septal defects ranked third. As reported in other studies there was a female preponderance at $56 \%$, with
$88 \%$ secundum type. ASDs tend to be well tolerated through infancy and childhood and are still diagnosed into adulthood.

We postulate that very few children of neonatal coarctation were seen because they are not referred early to our center and could have been missed by the primary health care provider. Critical neonatal coarctation often presents as an emergency with a new born in shock and fatal without immediate intervention ${ }^{21-23}$. Similarly, aortic coarctation among older children was rare. This may imply a low prevalence of this condition or show that man of these patients are not detected because blood pressure measurements are not routinely carried out in children $^{22}$. The few cases in our study presented after 5 years of age. It has also reported in the Nigerian Congenital Heart Disease registry that coarctation of the aorta was one of the rare $\mathrm{CHD}^{12}$.

Tetralogy of Fallot remains the most common cyanotic heart defect as has been reported elsewhere $e^{2,24,25}$. There is a relatively large population of unrepaired patients alive which implies greater survival in less severe cases. This trend has improved with more patients accessing corrective surgery that is now available at the Uganda Heart Institute. By 2014, 80\% of the open heart surgeries were performed by our local team and only $20 \%$ were referred abroad who mainly included complex congenital heart defects ${ }^{23}$.

Five percent of the patients had Truncus arteriosus which is higher than what is reported in other settings that give an overall prevalence of $2.4 \%{ }^{26,27}$. This was reflected consistently in the number of cases detected on a yearly basis over the study period. Most cases were diagnosed early (before 6 months) owing to an early presentation with heart failure. No new cases were seen in children above 5 years. Truncus arteriosus is associated with a high prevalence of genetic disorders. Thirty-nine percent of the children who underwent genetic testing had truncus arteriosus. This strongly suggests a genetic etiology in our population.

Cases of D-TGA were rare in the study. Transposition of the great arteries has been associated with a high mortality as reported in some studies?. The advent of palliative atrial septostomy at the Uganda Heart Institute that acts as a bridge to surgery, offers hope to these critically ill infants who may present with TGA with restrictive interatrial shunts.

Other complex defects were most prevalent in the first year of life. These were not diagnosed after the first birthday. They have been associated with a high mor- 
tality, two thirds of children with complex heart defects such as Hypoplastic left/right heart syndrome do not cerebrate their first birth day5. Unfortunately, limited treatment options are available in the country for such children.

We noted that some CHDs were rare in our study population, a case in point TAPVC (3\%) prevalence was comparable to that reported in the Nigerian Congenital Heart Registry (12). Others; Aortopulmonary window, Ebstein's anomaly and bicuspid aortic valve.

Genetic studies though limited, had a high likely hood of a positive result indicating a need for routine genetic screening in children with congenital heart disease. Deletion 22q11.2 which is associated with immunodeficiency, hypocalcaemia and learning difficulties was also been diagnosed by our team based on clinical findings. Prior knowledge of a genetic syndrome improves surgical outcomes for patients, given the fact that the surgical teams plan for any related complications for such abnormalities. Doell and friends in Switzerland reported no difference between children with genetic syndromes versus those without who underwent open heart surgery for $\mathrm{CHD}$, a genetic syndrome was an independent risk factor for re intubation, and kidney injury ${ }^{28}$.

Digital archiving enabled cases to be discussed with colleagues from other centers and there was an opportunity for re-evaluation of cases at follow up which improved diagnostic accuracy.

Our major limitation was having a retrospective study at a single site whose results may not be fully representative of the nation. However, two other sites have been established in the northern and western parts of the country.

\section{Conclusion}

Congenital heart disease is common among children. VSD, PDA and ASD were the commonest acyanotic heart defects while Tetralogy of Fallot and Truncus arteriosus topped the cyanotic defects. Genetic studies are called for in our population to further understand this high prevalence of Truncus arteriosus.

\section{Acknowledgments}

We would like to thank all children and families that contributed to this work. Ms Allen Nakiboneka who assisted with the analysis of this data and the entire department of paediatric cardiology.

\section{References}

1. Suzanne M. Gilboa, Jason L. Salemi, Wendy N. Nembhard, David E. Fixler, Adolfo Correa. Mortality Resulting from Congenital Heart Disease Among Children and Adults in the United States, 1999 to 2006. Circulation. 2010; 122: 2254-2263 PubMed

2. Charlotte Ferencz JR, Robert Mccarter. Congenital Heart Disease: prevalence at live birth, The Baltimore-Washington infant study. American Journal of Epidemiology. 1985;121(1):31-6.

3. Eloi Marijon AT, Sébastian Voicu et al. Prevalence of congenital heart disease in schoolchildren of sub-Saharan Africa, Mozambique 2006 Volume 113, Issue 3, Pages 440-441

4. Tantchou Tchoumi J C, Giamberti A, Ambassa JC, Sadeu JC. Occurrence and pattern of congenital heart diseases in a rural area of sub-Saharan Africa. Cardiovascular Journal of Africa. 2010;21(00).

5. Thakur JS NP, Ahluwalia SK, et al. Integrated community-based screening for cardiovascular diseases of childhood. World Health Forum. 1997;18(1):24-7. PubMed

6. Tantchou T J, Kingue S, Giamberti A, Cirri S, Frigiola A, Butera A. Occurrence, aetiology and challenges in the management of congestive heart failure in sub-Saharan Africa: Experience of the Cardiac Centre in Shisong, Cameroon. Pan African Medical Journal. 2011; Vol 8(1).

7. Leo Lopez, Steven D. Colan, Peter C. Frommelt, Gregory J. Ensing, Kathleen Kendall, Adel K. Younoszai, Wyman W. Lai, and Tal Geva, Recommendations for Quantification Methods During the Performance of a Pediatric Echocardiogram: Journal American Society Echocardiography 2010;23:465-95.

8. http://www.uvri.go.ug/news/uvri-hiv-reference-laboratory-receives-accreditation-college-american-pathologists-28th August 2019.

9. Lars Erik Carlgren. The incidence of congenital heart disease in children born in Gothenburg 1941-1950. Department of Pediatrics, University of Gothenburg, Sweden (1958).

10. Asuquo U. Anita Congenital heart disease in Nigeria Clinical and necropsy study of 260 cases. Archives of Disease in Childhood, 1974, 49, 36.

11. M. J. Mclaren, A. S. Lachman, and J. B. Barlow: Prevalence of congenital heart disease in black school children of Soweto, Johannesburg, British Heart Journal, 1979, 41, 554558 
12. Ekanem N. Ekure, Fidelia Bode-Thomas, Wilson E. Sadoh, Adeola A. Orogade et al. Congenital Heart Defects in Nigerian Children: Preliminary Data from the National Pediatric Cardiac Registry. World Journal for Pediatric and Congenital Heart Surgery 2017; Vol. 8(6) 699 706

13. Sadoh WE UC, Danies Q. Congenital heart diseases in Nigerian Children: a multicenter echocardiography study. World Journal of Pediatric Heart Surgery 2013;4(2):172-6

14. Maria Gillam-Krakauer and Jeff Reese. Diagnosis and Management of Patent Ductus Arteriosus. Neoreviews. 2018; 19(7): e394-e402.

15. http://www.everypreemie.org/wp-content/uploads/2016/02/Uganda.pdf(18/october 2017)

16. Malachi Ochieng Arunda, Anette Agardh and Benedict Oppong Asamoah. Survival of low birthweight neonates in Uganda: analysis of progress between 1995 and 2011. BMC Pregnancy and Childbirth (2018) 18:189 17. F.T. Cutts, S.E. Robertson, JL. Diaz-Ortega, R. Samuel: Control of rubella and congenital rubella syndrome (CRS) in developing countries, part 1: burden of disease from CRS, Bulletin of the World Health Organization, 1997, 75 (1): 55-68.

18. Fatemeh Vaziri, Shahla Roodpeyma, Manuchehr Hekmat. Cardiovascular Malformations in Congenital Rubella Syndrome: A Case Report, The Iranian Journal of Cardiac Surgery. 2011, May 60-62.

19. Barnabas Bakamutumaho, Judith Namuyonga, Mathew Cummings, James Eliku, Peter Lwabi, Sulaiman Lubega et al. Congenital rubella syndrome and associated chronic childhood disability in Uganda: implications for control, prevention, and vaccine policy -unpublished data.
20. http://health.go.ug/programs/uganda-national-expanded-program-immunisation-unepiUNEPI Immunization guidelines.

21. Ing FF, Stac TJ, Griffiths SP, Gersony WM: Early diagnosis of coarctation of the aorta in children: a continuing dilemma, Pediatrics. 1996 Sep;98(3 Pt 1) 378-82 22. Maureen A. Strafford, Sylvia P. Griffiths, Welton M. Gersony: Coarctation of the Aorta: A Study in Delayed Detection, Pediatrics 1982, February vol 62, 2

23. Aliku T, Lubega S, Namuyonga J, Mwambu T, Lwabi P, Sable C: Pediatric Cardiovascular Care in Uganda: Current status, Challenges and opportunities for the future Annals of Paediatric Cardiology. Ann Pediatric Cardiology. 2017 Jan-Apr; 10(1): 505.

24. Smitha R, Karat SC, Narayappa D et al. Prevalence of Congenital Heart Diseases in Mysore. Indian Journal of Human Genetics 2016;12(1):11-16

25. Barakat Adeola Animasahun, Akpoembele Deborah Madise-Wobo, Samuel I Omokhodion, Olisamedua Fidelis Njokanma. Children with Tetralogy of Fallot in an Urban Centre in Africa: J Cardiovasc Thoracic Res, 2015, 7(4), 168-171

26. Calder R, Van Praagh R, Van Praagh S, et al. Truncus arteriosus communis. Clinical, angiocardiographic, and pathologic findings. Am Heart J 1976; 92(1): 23-38. 27. Barakat Adeola Animasahun, Aminat Titilayo Ogunlana, and Henry Olusegun Gbelee. The Burden of Truncus Arteriosus in an Urban City in Africa: How are we Fairing? Heart Views. 2017;18(4): 121-124

28. Doell C, Bernet V, Morinari L Et al. Children with genetic disorders undergoing open-heart surgery: are they at increased risk for postoperative complications? Pediatr Crit Care Med. 2011 Sep;12(5):539-44 